\title{
Enhancement of Solubility and Dissolution Rate of Atazanavir Sulfate by Nanocrystallization
}

\author{
Vedanshu Malviya ${ }^{1, \star}$, Prashant Burange ${ }^{2}$, Yashdeepsingh Thakur ${ }^{2}$, Mukund Tawar ${ }^{2}$ \\ 1Department of Pharmaceutics, P.R. Pote Patil College of Pharmacy, Kathora, Amravati, Maharashtra, INDIA. \\ ${ }^{2}$ Department of Pharmaceutical Chemistry, P.R. Pote Patil College of Pharmacy, Kathora Road, Amravati, Maharashtra, INDIA.
}

\begin{abstract}
Objectives: The current objective of the present study was to enhance the solubility and dissolution rate of the antiviral drug atazanavir sulphate by employing nanocrystallization technique. Materials and Methods: The method employed for increment of solubility was nanocrystallization which is based on the reduction of particle size of the drug thereby increasing its solubility and also its dissolution property. Various polymers in different ratios were used like HPMC K15M, PVP K30 and PEG 6000. Results: Drug and polymers were firstly tested for their interaction between each other's and it was found that the drug and polymers are compatible with each other. From the solubility study it was seen that the solubility of the optimized batch was increased to $40.068 \mathrm{mg} / \mathrm{ml}$ in distilled water and $160.182 \mathrm{mg} / \mathrm{ml}$ in phosphate buffer while the pure drug shows the solubility of $4.174 \mathrm{mg} / \mathrm{ml}$ in distilled water and $20.547 \mathrm{mg} / \mathrm{ml}$ in phosphate buffer. The percent drug release of the optimized formulation was seen of $87.91 \%$ in $2 \mathrm{hrs}$ which was maximum from all the other batches. The stability study revealed that the prepared nanocrystal does not show any insignificant changes and therefore it can be concluded as stable. Conclusion: The prepared nanocrystals are the proof that this method of nanocrystallization may prove to be an efficient method in increasing the solubility and dissolution rate of the drug which are having low solubility and low bioavailability.
\end{abstract}

Key words: Atazanavir Sulphate, Nanocrystallization, Solubility Enhancement, Dissolution Enhancement, Antiviral.

\section{INTRODUCTION}

Lower solubility of an active drug substance may hinder the dissolution rate and absorption of the drug which can lead to lower bioavailability initiating the use of high amount of dose of the drug. Higher amount of drug can cause various adverse effects leading to damage to the body. Therefore it becomes essential to improve the solubility of the drug so that it will increase the dissolution of the drug. For oral administration, conventional formulations of poorly water-soluble drugs are associated with erratic absorption in the GI tract and low/variable bioavailability. ${ }^{1-4}$ Thus, bioavailability of poorly water-soluble drugs will be affected positively when their dissolution rate is increased.
Nanocrystallization is a method to scale back the particle size of the drug as nanosized particle which can be made into a powder or suspension in liquid which will cause an efficient area increment within the diffusion layer, which can eventually increases the dissolution rate of the drug. Nanonization of nonwater loving drugs generally involves the manufacturing nanocrystals through either disintegration or chemical precipitation..$^{5-7}$ The nanosuspensions prepared for crystallization will need solvent elimination process to induce a redispersible powder. ${ }^{8}$ Atazanavir acts by selectively prohibiting the virus-specific processing of viral Gag and Gag-Pol polyproteins in HIV-1 infected cells by binding to the positioning of HIV-1
Submission Date: 24-11-2020; Revision Date: 19-05-2021; Accepted Date: 24-08-2021

DOI: 10.5530/ijper.55.3s.174 Correspondence:

Prof. Vedanshu Malviya, Department of Pharmaceutics, P.R. Pote Patil College of Pharmacy, Kathora

Road-444604, Maharashtra, INDIA.

Phone: +91 0721-2568595, Email - vedanshumlv56@ gmail.com

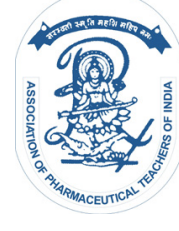

www.ijper.org 
protease. This prevents the formation of mature virions. But atazanavir is not active against HIV-2. Atazanavir gets extensively metabolized in humans, primarily within the liver. Mono-oxygenation and dioxygenation are the major biotransformation pathways of atazanavir in humans. Atazanavir is rapidly absorbed and has $\mathrm{T}_{\max }$ of roughly $2.5 \mathrm{hrs}$. It has been reported that bioavailability of atazanavir gets enhanced when administered with food and reduces pharmacokinetic variability. Oral bioavailability is found to be $60-68 \%$.912

In the current method the method applied was nanocrystallization and this method is employed here to overcome with the physical instability of drug when converted to various polymorphic forms.

\section{MATERIALS AND METHODS Materials}

Atazanavir Sulphate was supplied by Yarrow Chem, Mumbai India. HPMC K15M was obtained as a gift sample from Colorcon India, Goa. PVP K30 and PEG 6000 were procured from S.D. Fine Chem Pvt. Ltd. Mumbai, India. All other reagents and chemicals were used as obtained and were of analytical grades.

\section{Methods}

\section{Drug- Excipients Interaction Study}

The drug-excipient interaction study was carried out by employing FT-IR and DSC study. The study by FTIR of the drug and excipient was carried out by conventional $\mathrm{KBr}$ plate method in order to study the interaction of the drug and polymer so as to determine the physical as well as chemical changes that can occur during the formulation. For this the mixture of powder of excipient and pure was mixed in a ratio of 1:1 with potassium bromide and the small pellet was formed by pressing the mixture in a hydraulic press and the FT-IR was carried out in the frequency range $400-4000 \mathrm{~cm}^{-1}$. The predominant peaks were recorded and were matched with standard FTIR. ${ }^{13}$

\section{DSC Study}

The DSC study was carried out by studying thermograms of pure drug and its physical mixture with polymers was carried out to investigate any possible interaction between the drug and the utilized polymer. The selected heating rate is from $50^{\circ} \mathrm{C}$ to $400^{\circ} \mathrm{C}$ at an increase of $20^{\circ} \mathrm{C}$ per minute using Differential Scanning Calorimeter. ${ }^{14}$

\section{Standard Calibration Curve}

The standard calibration curve of Atazanavir Sulphate was carried out on UV spectrophotometer by using phosphate buffer of pH 7.4 as the solvent. From the solution which is now having a concentration of $100 \mu \mathrm{g} / \mathrm{ml}$ samples of $0.5,1,1.5,2,2.5,3,3.5,4,4.5$ and $5 \mathrm{ml}$ were pipette out into $10 \mathrm{ml}$ volumetric flasks. The volume was made up to the mark with Phosphate buffer 7.4 to get the final concentration of $5,10,15$, $20,25,30,35,40,45$ and $50 \mu \mathrm{g} / \mathrm{ml}$ respectively. ${ }^{15}$ The absorbance of concentration was measured at $250 \mathrm{~nm}$.

\section{Preparation of Atazanavir Sulphate Nanocrystals}

From the results of preformulation studies the 3 types of polymers were chosen i.e. HPMC K15M, PVP K30 and PEG 6000. The nanocrystals of atazanavir sulphate were prepared by the steps i.e. Formulation of atazanavir sulphate nanosuspensions and Lyophilization of nanosuspensions. Accurately weighed amount of drug sample was added $(200 \mathrm{mg})$ to methanol $(10 \mathrm{ml})$ to prepare the drug solution. The prepared drug solution is then added into required quantity $(10 \mathrm{ml})$ of water which contains various concentrations of stabilizers with continuous stirring on mechanical stirrer for $2 \mathrm{hrs}$ at $1000 \mathrm{rpm}$. After this the organic solvent is removed by stirring it again for $4-5 \mathrm{hrs}$ at $500 \mathrm{rpm}$. After the preparation of nanosuspensions the cryoprotective agent i.e. mannitol is added into it and the nanosuspensions are lyophilized by using deep freeze technique to enhance the chemical stability of nanocrystals. ${ }^{16-18}$ Atazanavir sulphate nanosuspensions were then rapidly cooled down to $-20^{\circ} \mathrm{C}$ for up to $2 \mathrm{hrs}$. The formulation chart is depicted in Table 1.

\begin{tabular}{|c|c|c|c|c|}
\hline \multicolumn{5}{|c|}{ Table 1: Formulation Chart of Nanocrystals. } \\
\hline Batch & $\begin{array}{c}\text { Drug } \\
\text { (mg) }\end{array}$ & $\begin{array}{c}\text { HPMC } \\
\text { K15M (\%) }\end{array}$ & $\begin{array}{c}\text { PVP K30 } \\
\text { (\%) }\end{array}$ & $\begin{array}{c}\text { PEG 6000 } \\
\text { (\%) }\end{array}$ \\
\hline A1 & 200 & 0.1 & - & - \\
\hline A2 & 200 & 0.2 & - & - \\
\hline A3 & 200 & 0.3 & - & - \\
\hline A4 & 200 & 0.4 & - & - \\
\hline A5 & 200 & 0.5 & - & - \\
\hline B1 & 200 & - & 0.1 & - \\
\hline B2 & 200 & - & 0.2 & - \\
\hline B3 & 200 & - & 0.3 & - \\
\hline B4 & 200 & - & 0.4 & - \\
\hline B5 & 200 & - & 0.5 & - \\
\hline C1 & 200 & - & - & 0.1 \\
\hline C2 & 200 & - & - & 0.2 \\
\hline C3 & 200 & - & - & 0.3 \\
\hline C4 & 200 & - & - & 0.4 \\
\hline C5 & 200 & - & - & 0.5 \\
\hline
\end{tabular}




\section{Characterization of Nanocrystals}

\section{Percent Drug Content}

Samples containing $100 \mathrm{mg}$ of atazanavir sulphate crystals were accurately weighed and dissolved in phosphate buffer of $\mathrm{pH} 6.8$ and sonicated for $10 \mathrm{~min}$. The solution is then filtered using a whatman filter paper from the above solution $10 \mathrm{ml}$ is pipette out and made up to $100 \mathrm{ml}$ using phosphate buffer of $\mathrm{pH}$ 6.8. The resultant solution is then analyzed spectrophotometrically at $250 \mathrm{~nm}$ and then the percent drug content is estimated. ${ }^{19}$

\section{In-vitro Dissolution Study}

USP dissolution apparatus Type I (basket type) was used to study the drug release behavior of pure drug and nanocrystals. Dissolution behavior of pure Atazanavir sulphate and nanocrystals was studied using phosphate buffer $\mathrm{pH} 6.8$ as dissolution medium. Drug $(1000 \mathrm{mg})$ in muslin cloth which was tightly tied was placed in basket containing $900 \mathrm{ml}$ of solution of $\mathrm{pH} 6.8$ for $2 \mathrm{hrs}$. After each regular interval of time $5 \mathrm{ml}$ of solution was withdrawn and diluted with buffer 6.8 solution. After each withdrawal of the samples the fresh dissolution medium was added into the apparatus in order to maintain the sink condition. The diluted samples were then analyzed at $250.0 \mathrm{~nm}$ using UV-spectrophotometer. ${ }^{20}$ The cumulative drug release (\% CDR) was then calculated for every batch of nanocrystals containing different polymers.

\section{Kinetics Study}

The drug release data were fitted to zero order (cumulative vs. $\%$ drug release versus time), first order (log of cumulative vs. $\%$ drug retained versus time), and Higuchi models (cumulative vs. \% drug released versus square root of time) and Korsmeyer-Peppas model (log of \%cumulative drug release vs. log of time) to calculate the kinetics of drug release and determine the release mechanism of the drug from the prepared nanocrystals.

\section{Determination of Particle size and Zeta potential}

The mean particle size and zeta potential of atazanavir sulphate nanocrystals formulations are determined by dynamic light scattering technique using a zeta size analyzer. The freeze dried nanocrystals are re-dispersed with water to obtain a proper scattering intensity before analysis.

\section{Solubility Studies}

Solubility of atazanavir sulphate nanocrystals were studied in different solvents such as distilled water and phosphate buffer $\mathrm{pH}$ (6.8). Pure drug and an excess amount of nanocrystal formulation were added in
$10 \mathrm{ml}$ of the chosen solvents. The mixtures are mixed in a mechanical stirrer for $24 \mathrm{hrs}$. Visual inspection is carefully made to ensure there are excess atazanavir sulphate solids in the mixture, indicating saturation have been reached. ${ }^{21,22}$ The mixtures are then filtered and the resultant solution was diluted suitably to determine the solubility of atazanavir sulphate in each solvent by using UV spectrophotometer at $250 \mathrm{~nm}$.

\section{X-ray Diffraction Study (XRD)}

X-ray diffraction spectra of atazanavir sulphate and prepared nanocrystals were recorded with $\mathrm{x}$-ray diffractometer employing a voltage of $45 \mathrm{Kv}$ and a current of $40 \mathrm{~mA}$. The instrument was operated in continuous scan mode over $2 \theta$ range at $20^{\circ}-80^{\circ}$. The relative intensity $\mathrm{I} / \mathrm{I} 0$ and interplanar distance (d) like the $2 \theta$ values were reported and compared. ${ }^{23}$

\section{Head Space Gas Chromatography}

For the determinations of content of methanol in the prepared nanocrystals that may be get entrapped in the preparation HS-GC was employed in order to determine the amount of methanol that should be in least amount and safe for human consumption. For this accurately weighed optimized nanocrystals were suspended in methanol and shaken in orbital shaking incubator for $24 \mathrm{hrs}$ at $100 \mathrm{rpm}$. Subsequently, the dispersion was filtered and filtrate was analyzed using HS-GC with column Rtx- 5MS and Helium as carries gas. The reference solution (1000 ppm) and sample solution were injected alternatively to HS-GC and area of peak obtained was used to calculate the solvent concentrate in the optimized formulation. ${ }^{23}$ The permitted daily exposure methanol according to $\mathrm{ICH}$ is $300 \mathrm{ppm}^{24}$

\section{Scanning Electron Microscopy (SEM)}

Scanning electron microscopy of atazanavir sulphate and prepared nanocrystals were taken using scanning electron microscope. The form and surface morphology were observed using SEM. The nanocrystals were observed at various magnifications so as to research the effect of additives on surface morphology and crystallization efficiency. ${ }^{25}$

\section{Stability Study}

The stability of the optimized formulation was carried out accordingly as per the guidelines of International Council for Harmonization (ICH). The stability study was carried out as accelerated study at $40^{\circ} \mathrm{C} \pm 2{ }^{\circ} \mathrm{C} / 75$ $\% \mathrm{RH} \pm 5 \% \mathrm{RH}$ for 90 days. The optimized formulation was studied for the parameters such as solubility study and dissolution rate. ${ }^{26}$ 


\section{RESULTS AND DISCUSSION}

\section{Drug- Excipients Interaction Study}

The study of FT-IR spectrum of pure drug exhibited characteristic peaks at 3357.84, 3060.82 and 2873.74 $\mathrm{cm}^{-1}$ corresponding to the stretching vibrations of $\mathrm{N}-\mathrm{H}$, aromatic $\mathrm{C}-\mathrm{H}$ and asymmetric and symmetric aliphatic C-H stretching respectively. The presence of amide group in the structure was also confirmed by $\mathrm{C}=\mathrm{O}$ stretching at $1699.17 \mathrm{~cm}^{-1}$ and $\mathrm{N}-\mathrm{H}$ deformation band at $1650.95 \mathrm{~cm}^{-1}$. Though the fingerprint region of drug and nanocrystals were not super imposable due to the presence of polymer in nanocrystals, but almost identical prominent absorption bands were obtained from FTIR spectrum of optimized nanocrystals but with somewhat lower intensity. From the study it was concluded that the drug and excipients used were compatible with each other and does not have any interaction between them. The results can be seen in Figure 1.

\section{DSC Study}

DSC thermograms of atazanavir sulphate showed a single sharp characteristic endothermic peak at $211.7^{\circ} \mathrm{C}$ corresponding to its melting point, indicating its crystalline nature. This sharp peak confirmed the purity of drug with no noticeable impurities present. Atazanavir sulphate was found to be stable to heat up to $200^{\circ} \mathrm{C}$ without any signs of moisture and phase transition. In the DSC thermogram of nanocrystals, endothermic
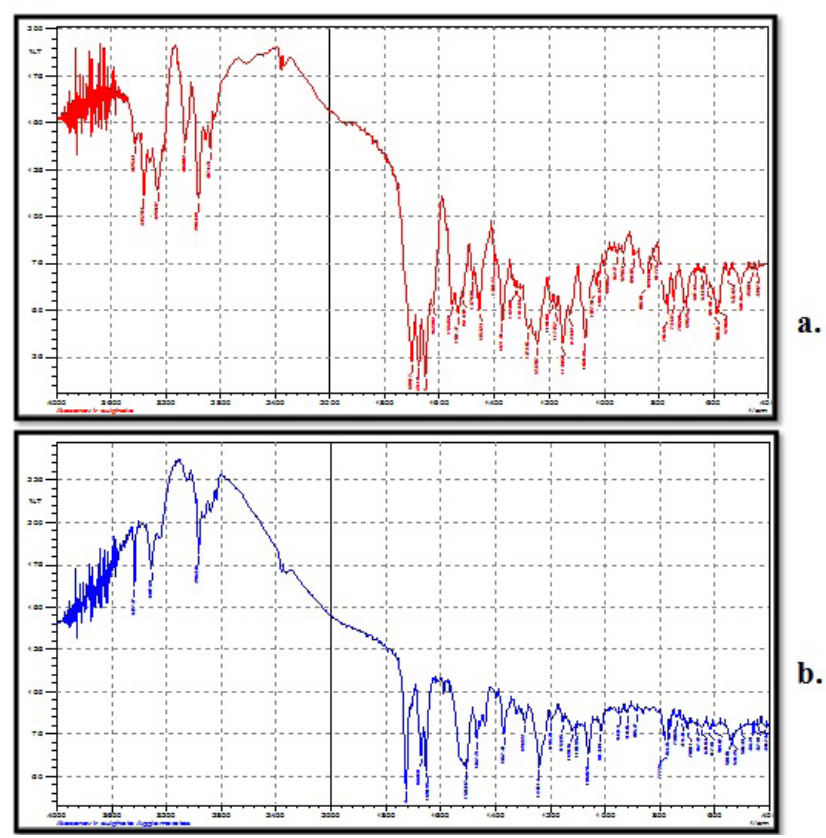

Figure 1: a) FTIR of Pure Drug Atazanavir Sulphate. b) FTIR of Optimized Formulation. peak correspond to atazanavir sulphate at $210.96^{\circ} \mathrm{C}$ with a significant reduction in heat of fusion/enthalpy $(\Delta \mathrm{H})$ of $19.08 \mathrm{~J} / \mathrm{g}$. This occurrence might be attributed to the dispersion of crystalline atazanavir sulphate into amorphous polymer. Partial amorphization of crystalline atazanavir sulphate in nanocrystals might also be a reason. Partial amorphization of drug might provide comparatively more stability than their complete amorphous counterparts. Further, a small endothermic peak at $61.71^{\circ} \mathrm{C}$ in DSC thermogram of nanocrystals might be because of the evaporation of methanol solvent which was entrapped in crystals during formulation. These findings from Figure 2 clearly indicated a strong possibility of the transformation of atazanavir sulphate to its nanocrystals which might be responsible for improved dissolution.

\section{Standard Calibration Curve}

The standard calibration curve of pure atazanavir sulphate shows that it obeys the beers lamberts law as the equation obtained was linear. The equation obtained was $\mathrm{y}=0.014 \mathrm{x}+0.139$ and the value of $\mathrm{R}^{2}$ was found to be 0.997 as seen in Figure 3.

\section{Percent Drug Content}

From the drug content study it was seen that the drug content in the batch of A1-A5 the drug content range was between $88.00 \pm 1.8644$ - 93.63 $\pm 1.6226 \%$. B1-B5 shows the drug content range in between $90.33 \pm 1.0237$ $93.66 \pm 1.1547 \%$. The last batch of C1-C5 shows the drug

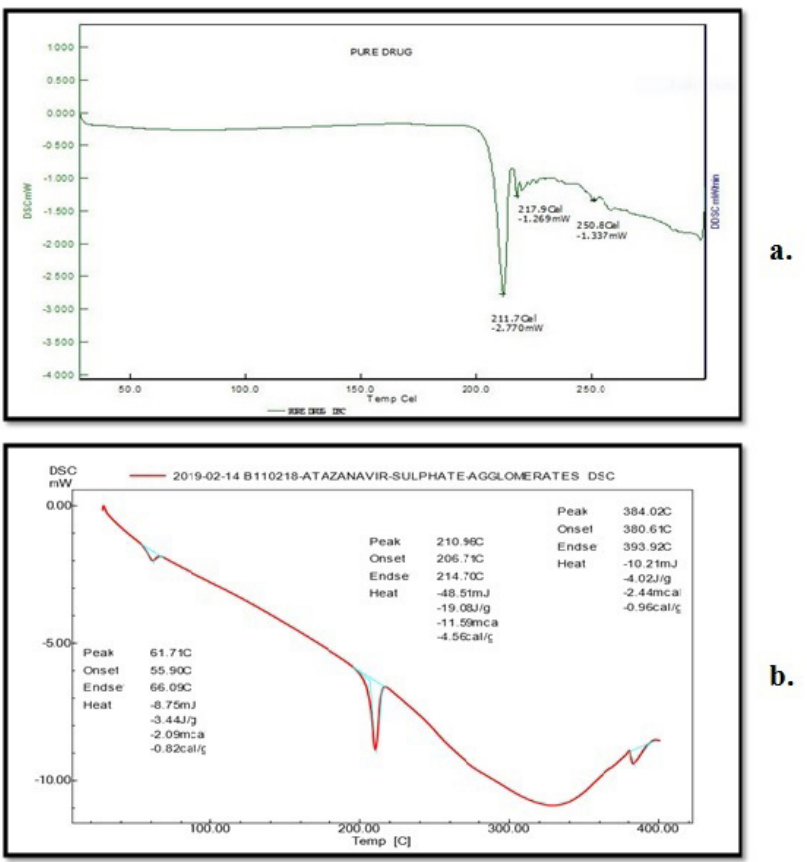

Figure 2: a) DSC of Pure Drug Atazanavir Sulphate. b) DSC of Optimized Formulation. 


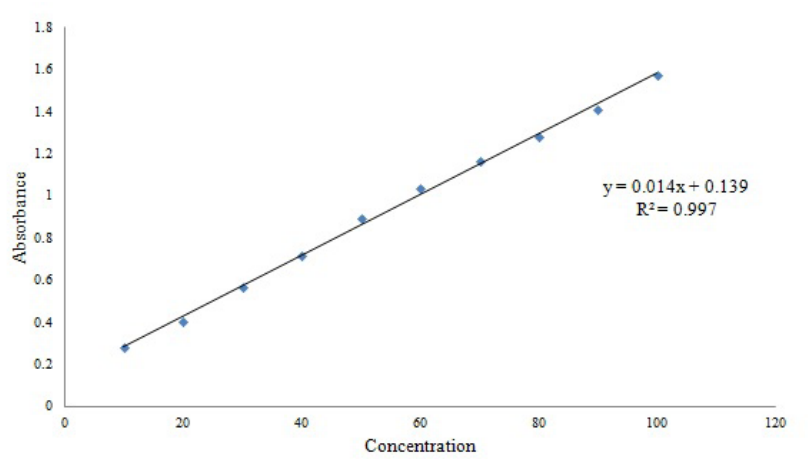

Figure 3: Standard Calibration Curve of Atazanavir Sulphate.

\begin{tabular}{|c|c|c|}
\hline \multicolumn{3}{|c|}{ Table 2: Percent Drug Content Study. } \\
\hline Sr. No. & Batch & Percent Drug Content (\%) \\
\hline 1. & A1 & $93.63 \pm 1.6226$ \\
\hline 2. & A2 & $89.63 \pm 1.9561$ \\
\hline 3. & A3 & $89.70 \pm 1.3856$ \\
\hline 4. & A4 & $88.00 \pm 1.8644$ \\
\hline 5. & A5 & $89.50 \pm 2.0621$ \\
\hline 6. & B1 & $92.86 \pm 1.8013$ \\
\hline 7. & B2 & $92.00 \pm 1.6055$ \\
\hline 8. & B3 & $90.33 \pm 1.0237$ \\
\hline 9. & B4 & $93.66 \pm 1.1547$ \\
\hline 10. & B5 & $93.00 \pm 1.4641$ \\
\hline 11. & C1 & $93.66 \pm 1.2748$ \\
\hline 12. & C2 & $95.33 \pm 0.5166$ \\
\hline 13. & C3 & $96.98 \pm 1.2784$ \\
\hline 14. & C4 & $95.33 \pm 1.5166$ \\
\hline 15. & C5 & $96.00 \pm 1.7320$ \\
\hline
\end{tabular}

$n=3^{*}$

content in the range of $93.66 \pm 1.2748-96.98 \pm 1.2784 \%$. Form all the results in the Table 2 it was seen that the maximum drug content in all the batches was of $\mathrm{C} 3$ which was $96.98 \pm 1.2784 \%$.

\section{In-vitro Dissolution Study}

The in-vitro dissolution studies of all formulations were compared with pure drug. The drug release of pure drug in the time span of $2 \mathrm{hr}$ was found to be $61.78 \%$. The percent cumulative study of the prepared nanocrystals revealed that the in-vitro release profiles of all the formulations are significantly greater than that pure drug atazanavir sulphate. The nanocrystals prepared from the stabilizer HPMC K15M in various ratios showed the drug release of $53.39 \%, 68.24 \%, 67.97 \%, 71.12 \%$ and 74.21\%. The drug release from PVP K30 as a stabilizer in various ratios showed the drug release of $73.29 \%$, $74.04 \%, 75.68 \%, 75.67 \%$ and $78.78 \%$. Lastly the drug release from PEG 6000 as a stabilizer in various ratios showed the drug release from $60.46 \%, 72.49 \%, 78.69 \%$, $81.02 \%$ and $87.91 \%$ respectively. From all the data obtained from the dissolution study it was concluded that the batch of C5 from PEG 6000 was having the maximum drug release rate of $87.91 \%$ which is higher than compared with the other batches. The batch of C5 can be considered as the optimized batch because the increased percentage drug release of stabilizer (PEG 6000) having formulation (C1-C5) indicates that, stabilizer PEG 6000 had long hydrophilic chain and it captured the water molecule through hydrogen bonding, which were formed between the hydroxyl group and ether bond of PEG and water molecule, in order to improve the drug dissolution rate. The results can be seen in Figure 4.

\section{Kinetics Study}

From the results of kinetics study as shown in Table 3 it can be seen that the prepared optimized formulation possesses a drug release by korsmeyers-peppas model of diffusion with the $R^{2}$ value of 0.9711 .

\section{Determination of Particle size and Zeta potential}

Particle size, size distribution and zeta potential were important characterizations of the nanocrystals because they govern the other characterizations, such as saturation solubility and dissolution. In the present study the average diameters and polydispersity index of atazanavir sulphate nanocrystals was found to be in the range of $80.3 \mathrm{~nm}$ to $300.6 \mathrm{~nm}$. The average particle size of the optimized formulation i.e. C5 was found to be 100.8 $\mathrm{nm}$ as shown in Figure 5.

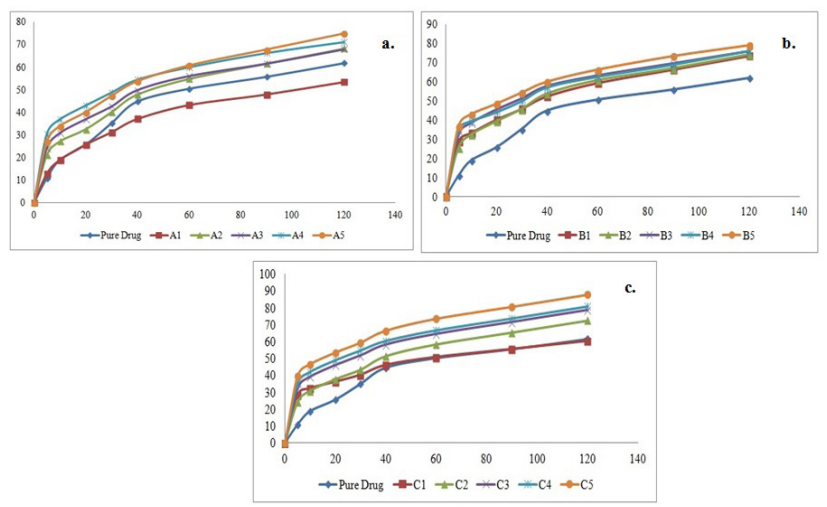

Figure 4: Percent Cumulative Drug Release of the prepared Nanocrystals.

a) Percent Drug Release of Nanocrystals using HPMC K15M. b) Percent Drug Release of Nanocrystals using PVP K30. c) Percent Drug Release of Nanocrystals using PEG 6000. 
Table 3: Kinetics Study of the Optimized Formulation.

\begin{tabular}{|c|c|c|c|c|c|}
\hline Batch & Zero Order $\left(R^{2}\right)$ & First Order $\left(R^{2}\right)$ & Higuchi $\left(R^{2}\right)$ & Korsmeyers-Peppas $\left(R^{2}\right)$ & Best Fit Model \\
\hline C5 & 0.6969 & 0.8726 & 0.9146 & 0.9711 & Korsmeyers-Peppas \\
\hline
\end{tabular}

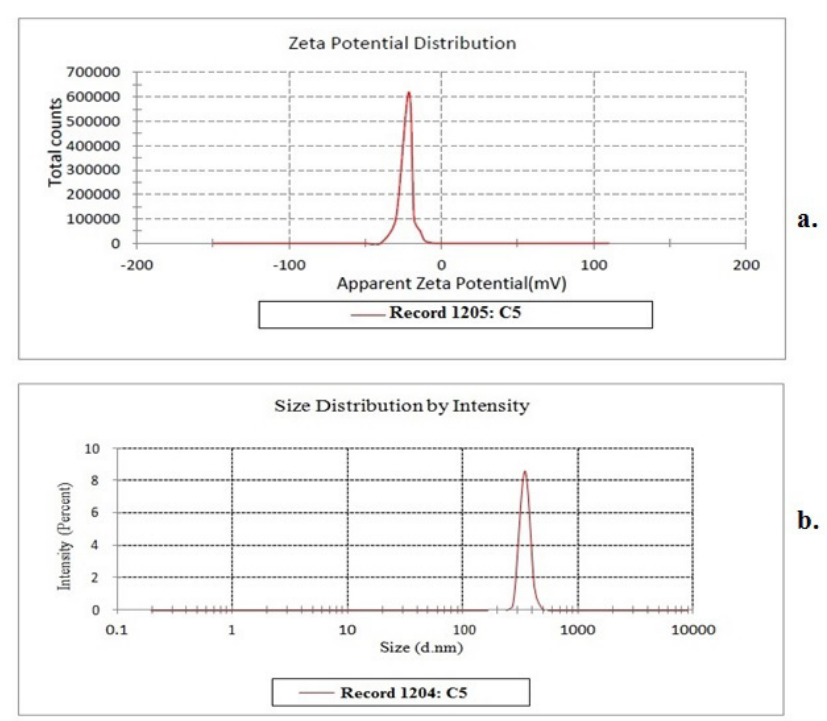

Figure 5: a) Zeta Potential of the Optimized Formulation.

b) Particle Size Analysis of Optimized Formulation.

The atazanavir sulphate nanocrystals were characterized to evaluate the effect of stabilizers at different ratios and different on surface charge of nanocrystals. Zeta potential values of the formulations prepared with different stabilizers showed negative zeta potential $(-19.7 \mathrm{mV}$ to $-24.7 \mathrm{mV}$ ) which indicated a stable preparation. The zeta potential of the optimized formulation was found to be $-21.4 \mathrm{mV}$ and the results were depicted in Figure 5.

\section{Solubility Studies}

The solubility study of the prepared nanocrystals and the pure drug was studied in distilled water and in phosphate buffer of $\mathrm{pH}$ 6.8. The formulations showing highest amount of drug release was chosen for the study with the optimized formulation. From the results it was clear that the optimized formulation was having the highest solubility of drug in the solvents selected for the test. The pure drug atazanavir sulphate showed the solubility of $4.174 \pm 0.02 \mathrm{mg}$ in distilled water and $20.547 \pm 0.05 \mathrm{mg}$ in phosphate buffer while the optimized formulation C5 showed the solubility of $40.068 \pm 0.09 \mathrm{mg}$ in distilled water and $160.182 \pm 0.14 \mathrm{mg}$ in phosphate buffer. The solubility of the prepared nanocrystals increased up to ten folds when compared to pure drug. The reason behind the solubility increment of atazanavir sulphate may be due to the decreased



Figure 6: Solubility Study of the Prepared Nanocrystals.

particle size and increased surface area. This solubility data is shown up in the Figure 6.

\section{X-ray diffraction study (XRD)}

The XRD pattern of atazanavir sulphate exhibited intense, sharp well resolved peaks whereas XRD pattern of prepared nanocrystals exhibited less intense and denser peaks compared to atazanavir sulphate. The XRD pattern of atazanavir sulphate showed its characteristics peaks at $2 \theta$ of $5.77,10.88,12.09,13.03,16.79,18.02$, $18.60,19.47,20.26,21.00,22.90$ and 23.36 which are the characteristic of a crystalline compound. This result from Figure 7 confirmed that the characteristic peaks were still preserved indicating the crystalline state was not changed.

\section{Head Space Gas Chromatography}

A residual solvent peaks of optimized atazanavir sulphate nanocrystals were observed at same retention times as that of standard i.e. $2.862 \mathrm{~min}$ methanol respectively with extremely low intensity. It depicted that the most of the solvents were evaporated and very small amount of solvents retained in nanocrystals. The results of this study as shown in Table 4 and Figure 8 revealed that the entrapped methanol was having a concentration of $10 \mathrm{ppm}$ and was in an insignificant extent and hence it does not produce toxicity in humans.

\section{Scanning electron microscopy (SEM)}

An examination of the SEM from Figure 9 of atazanavir sulphate confirmed that the pristine atazanavir sulphate was significantly smaller in particle size and blade shaped with fines. Improved solubility of modified 


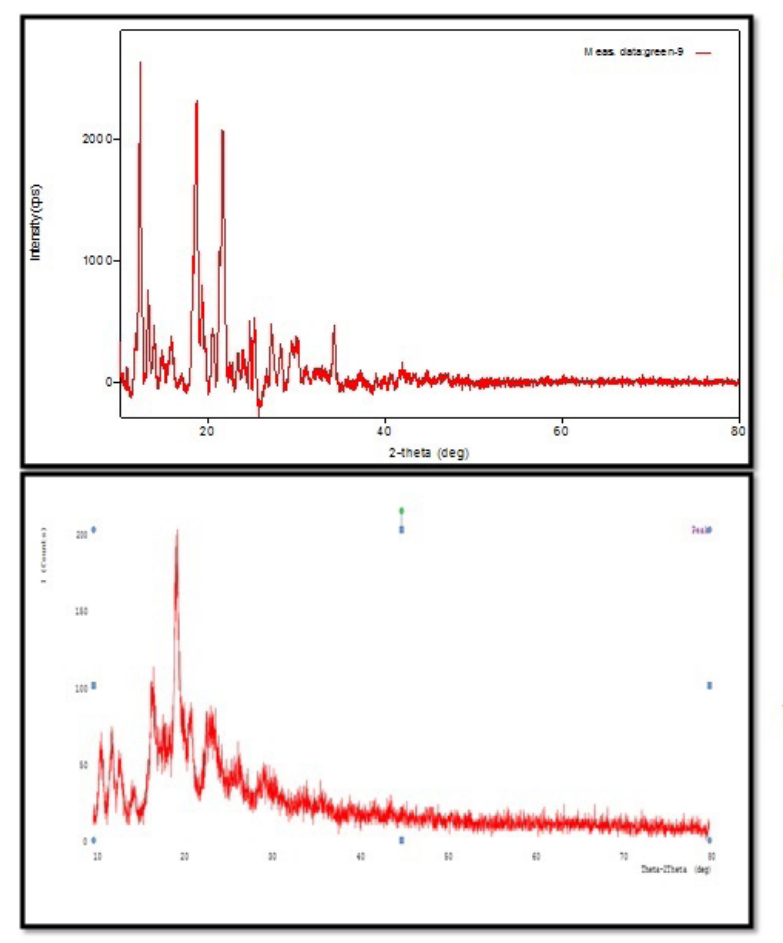

Figure 7: a) XRD Study of Pure Drug Atazanavir Sulphate. b) XRD Study of Optimized Formulation.

\begin{tabular}{|c|c|c|c|c|c|}
\hline Peak & $\begin{array}{c}\text { Component } \\
\text { Name }\end{array}$ & $\begin{array}{l}\text { Time } \\
{[\mathrm{min}]}\end{array}$ & $\begin{array}{c}\text { Area } \\
{[\mathrm{uVsec}]}\end{array}$ & $\begin{array}{c}\text { Height } \\
{[\mathrm{uV}]}\end{array}$ & $\begin{array}{c}\text { Area } \\
{[\%]}\end{array}$ \\
\hline 1 & \multirow[t]{3}{*}{ Methanol } & 2.250 & 105.08 & 39.74 & 1.41 \\
\hline \multirow[t]{2}{*}{2} & & 2.876 & 7325.64 & 2705.33 & 98.59 \\
\hline & & & $\begin{array}{c}= \\
7430.72\end{array}$ & $\begin{array}{c}= \\
2745.07\end{array}$ & $=100.00$ \\
\hline
\end{tabular}

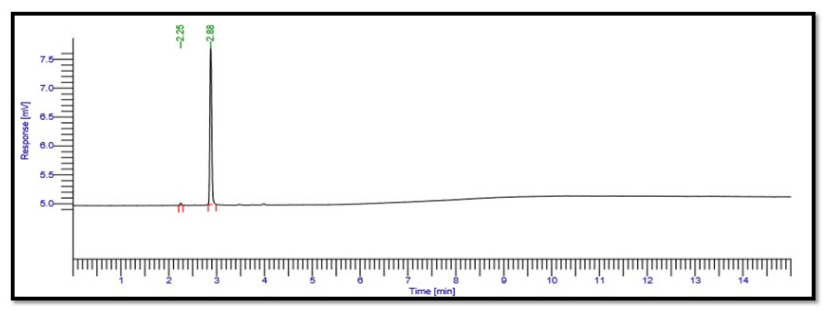

Figure 8: Results of Head Space Gas Chromatography for the Estimation of Methanol in Nanocrystals.

crystals obtained by nanocrystallization was an evidence of cylindrical shape of crystals.

\section{Stability Study}

From the results of stability study it was seen that the solubility of the prepared nanocrystals were having an insignificant change during the time period. There was

b.



a.

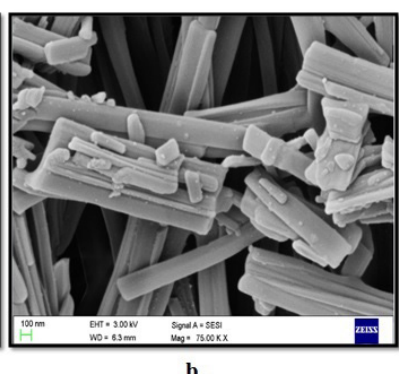

b.
Figure 9: a) SEM study of Pure Drug. b) SEM of Optimized Formulation.

Table 5: Stability Study of the prepared Nanocrystals at Accelerated Study $\left(40^{\circ} \mathrm{C} \pm 2^{\circ} \mathrm{C} / 75 \% \mathrm{RH} \pm 5 \% \mathrm{RH}\right)$.

\begin{tabular}{|c|c|c|c|c|}
\hline \multirow[t]{2}{*}{ Day } & \multirow[t]{2}{*}{ Batch } & \multicolumn{2}{|c|}{ Solubility Study (mg/ml) } & \multirow{2}{*}{$\begin{array}{l}\text { In-vitro Drug } \\
\text { Release (\%) }\end{array}$} \\
\hline & & $\begin{array}{l}\text { Distilled } \\
\text { Water }\end{array}$ & $\begin{array}{l}\text { Phosphate } \\
\text { Buffer (6.8) }\end{array}$ & \\
\hline 0 & \multirow[t]{5}{*}{ C5 } & $40.068 \pm 0.009$ & $160.068 \pm 0.14$ & 87.91 \\
\hline 15 & & $40.068 \pm 0.258$ & $160.068 \pm 0.25$ & 87.91 \\
\hline 30 & & $40.068 \pm 0.067$ & $160.068 \pm 0.11$ & 87.59 \\
\hline 60 & & $40.015 \pm 0.017$ & $159.197 \pm 0.12$ & 87.55 \\
\hline 90 & & $38.195 \pm 0.248$ & $159.186 \pm 0.87$ & 87.55 \\
\hline
\end{tabular}

$n=3$

a slight change in the solubility was can be negligible i.e. $40.068 \mathrm{mg} / \mathrm{ml}-38.195 \mathrm{mg} / \mathrm{ml}$ in distilled water and $160.068 \mathrm{mg} / \mathrm{ml}-159.186 \mathrm{mg} / \mathrm{ml}$ from 0 to 90 days and the percent drug release in $2 \mathrm{hrs}$ was decreased from $87.91 \%-87.55 \%$. All the changes found during the stability study were insignificant as shown in Table 5 and hence it can be concluded that the prepared formulation was stable.

\section{CONCLUSION}

The nanocrystals of atazanavir sulphate were prepared by employing emulsion solvent diffusion method. It was concluded that nanocrystallization was an excellent approach to enhance the solubility and dissolution property of atazanavir sulphate. The solubility and in vitro dissolution studies suggested that the nanocrystal formulations can improve the solubility and as well as the bioavailability of the atazanavir sulphate rate when compared to pure drug. Thus the adaptation of this method of nanocrystallization in the drug delivery system can increase the solubility and dissolution rate of poorly soluble drug like atazanavir sulphate to enhance their solubility and also it will enhance its absorption in the body giving maximum bioavailability in the body. 


\section{ACKNOWLEDGEMENT}

The authors are thankful to Yarrow Chem, Mumbai India for providing us with the API of Atazanavir Sulphate. The authors are also thankful to Colorcon India, Goa for providing us with the gift samples of HPMC K15M. The authors are also thankful to the management and Principal of P.R. Pote Patil College of Pharmacy, Amravati for providing us with the facilities for carrying out this research work. The authors are also thankful to Diya Labs, Mumbai for helping us with carrying out with the study of SEM and Zeta Potential.

\section{CONFLICT OF INTEREST}

The authors declare no conflict of interest.

\section{ABBREVIATIONS}

PVP: Polyvinyl Pyrollidine; HPMC: Hydroxypropyl Methyl Cellulose; GI: Gastro-Intestinal; HIV: Human Immunodeficiency Virus; FTIR: Fourier Transmission Infra-red; DSC: Differential Scanning Calorimetry; UV: Ultra Violet; USP: United States Pharmacopoeia; CDR: Cumulative Drug Release; XRD: X-Ray Diffraction; HSGC: Head-Space Gas Chromatography; SEM: Scanning Electron Microscopy; RH: Relative Humidity.

\section{REFERENCES}

1. Sathali $\mathrm{AH}$, Gopinath $\mathrm{G}$. Formulation and evaluation of paliperidone nanocrystals. J Biomed. Med. 2013;1(5):422-38.

2. Hecq J, Deleers M, Fanara D, Vranckx H, Amighi K. Preparation and characterization of nanocrystals for solubility and dissolution rate enhancement of nifedipine. Int J Pharm. 2005 Aug 11;299(1-2):167-77. doi: 10.1016/j.jpharm.2005.05.014, PMID 15996838.

3. Nagaraju K. An overview enhancement of solubility and dissolution rate. Int Res J Pharm Appl Sci. 2012 Oct 29;2(5):198-210.

4. Jain S, Patel N, Lin S. Solubility and dissolution enhancement strategies: current understanding and recent trends. Drug Dev Ind Pharm. 2015 Jun 3;41(6):875-87. doi: 10.3109/03639045.2014.971027, PMID 25342479.

5. Bajaj A, Rao MR, Pardeshi A, Sali D. Nanocrystallization by evaporative antisolvent technique for solubility and bioavailability enhancement of telmisartan. AAPS PharmSciTech. 2012 Dec;13(4):1331-40. doi: 10.1208/ s12249-012-9860-x, PMID 23054986.

6. Nagarwal C R, Kumar R, Dhanawat M, Das N, K Pandit J. Nanocrystal technology in the delivery of poorly soluble drugs: an overview. Current drug delivery. 2011 Jul 1;8(4):398-406.

7. Kumar R, Siril PF. Drop-by-drop solvent hot antisolvent interaction method for engineering nanocrystallization of sulfamethoxazole to enhanced water solubility and bioavailability. J Drug Deliv Sci Technol. 2020 Feb 1;55. doi: 10.1016/j.jddst.2019.101359, PMID 101359.
8. Kumar A, Nano Cocrystals NA. Crystal engineering from a nanotechnological perspective. Curr Pharm Des. 2021.

9. Bhirud $\mathrm{CH}$, Hiremath SN. Stability indicating RP-HPLC method for the determination of atazanavir sulphate in bulk and dosage form. Drug Invent Today. 2013 Jun 1;5(2):81-6. doi: 10.1016/j.dit.2013.05.008.

10. Kis O, Walmsley SL, Bendayan R. In vitro and in situ evaluation of $\mathrm{pH}$-dependence of atazanavir intestinal permeability and interactions with acid-reducing agents. Pharm Res. 2014 Sep;31(9):2404-19. doi: 10.1007/ s11095-014-1336-0, PMID 24595498.

11. Xia X, Zhou C, Ballell L, Garcia-Bennett AE. In vivo enhancement in bioavailability of atazanavir in the presence of proton-pump inhibitors using mesoporous materials. ChemMedChem. 2012 Jan 2;7(1):43-8. doi: 10.1002/ cmdc.201100500, PMID 22144293.

12. Berlin M, Ruff A, Kesisoglou F, Xu W, Wang MH, Dressman JB. Advances and challenges in PBPK modeling--Analysis of factors contributing to the oral absorption of atazanavir, a poorly soluble weak base. Eur J Pharm Biopharm. 2015 Jun 1;93:267-80. doi: 10.1016/j.ejpb.2015.03.031, PMID 25872159.

13. Malviya V, Ladhake V, Gajbiye K, Satao J, Tawar M. Design and characterization of phase transition system of zolmitriptan hydrochloride for nasal drug delivery system. Int J Pharm Sci Nanotechnol. 2020 May 31;13(3):4942-51. doi: 10.37285/ijpsn.2020.13.3.8.

14. Indrayanto G, Mugihardjo HR, Handayani R. Compatibility study between famotidine and some excipients using differential scanning calorimetry. Drug Dev Ind Pharm. 1994 Jan 1;20(5):911-20. doi: 10.3109/03639049409038340.

15. Malviya VR, Pande SD, Bobade NN. Preparation and evaluation of sustained release beads of zolmitriptan hydrochloride. Res J Pharm Technol. 2019;12(12):5972-6. doi: 10.5958/0974-360X.2019.01037.0.

16. Jacob S, Nair AB, Shah J. Emerging role of nanosuspensions in drug delivery systems. Biomater Res. 2020 Dec;24(1):3. doi: 10.1186/s40824-020-0184-8, PMID 31969986.

17. Kocbek P, Baumgartner S, Kristl J. Preparation and evaluation of nanosuspensions for enhancing the dissolution of poorly soluble drugs. Int J Pharm. 2006 Apr 7;312(1-2):179-86. doi: 10.1016/j.ijpharm.2006.01.008, PMID 16469459.

18. Pandya VM, Patel JK, Patel DJ. Formulation and optimization of nanosuspensions for enhancing simvastatin dissolution using central composite design. Dissolution Technol. 2011 Aug 1;18(3):40-5. doi: 10.14227/ DT180311P40.

19. Malviya VR, Tawar MG. Preparation and evaluation of oral dispersible strips of teneligliptin hydrobromide for treatment of diabetes mellitus. Int J Pharm Sci Nanotechnol. 2020 Jan 31;13(1):4745-52.

20. Ahuja M, Verma P, Bhatia M. Preparation and evaluation of chitosanitraconazole co-precipitated nanosuspension for ocular delivery. J Exp Nanosci. 2015 Feb 11;10(3):209-21. doi: 10.1080/17458080.2013.822108.

21. Marın MT, Margarit MV, Salcedo GE. Characterization and solubility study of solid dispersions of flunarizine and polyvinylpyrrolidone. Farmaco. $2002 \mathrm{Sep}$ 1;57(9):723-7. doi: 10.1016/s0014-827x(02)01262-4, PMID 12385522.

22. Baka E, Comer JE, Takács-Novák K. Study of equilibrium solubility measurement by saturation shake-flask method using hydrochlorothiazide as model compound. J Pharm Biomed Anal. 2008 Jan 22;46(2):335-41. doi: 10.1016/j.jpba.2007.10.030, PMID 18055153.

23. Snow NH, Slack GC. Head-space analysis in modern gas chromatography. TrAC Trends Anal Chem. 2002 Sep 10;21(9-10):608-17. doi: 10.1016/S01659936(02)00802-6.

24. Guideline IH. Impurities: guideline for residual solvents Q3C. 2005 Nov;4;R5. Current Step:1-25.

25. Sridev D, Rajendran KV. Synthesis and optical characteristics of ZnO nanocrystals. Bull Mater Sci. 2009 Apr 1;32(2):165-8. doi: 10.1007/s12034009-0025-9.

26. Lin TY, Chen CW. Overview of stability study designs. J Biopharm Stat. 2003 Jan 7;13(3):337-54. doi: 10.1081/BIP-120022759, PMID 12921386. 
PICTORIAL ABSTRACT



About Authors

Prof. Vedanshu Malviya is currently working at P.R. Pote Patil College of Pharmacy, Amravati. He is currently working in the Department of Pharmaceutics and has more than 2 years of academics experience. He is having publications in many National and International Journals. He is having an interest in Novel Drug Delivery along with Formulation and Developement.

\section{SUMMARY}

The current study was performed in order to carry out the solubility enhancement and dissolution rate of atazanavir sulphate by nanocrystallization technique. In this method various polymers were used as stabilizing agents in various ratios. As the drug is water insoluble the nanocrystals were prepared in order to increase its solubility. The prepared nanocrystals were tested in various solvents and it was found that the solubility is increased at a good percentage. Now as the solubility is increased this factor also lead to its increased drug release property i.e. dissolution rate is increased when compared with the drug release with pure drug only. PEG 6000 was seen as the best stabilizer for solubility enhancement as the hydroxyl group and ether bond of PEG and water molecule may be responsible for its solubility enhancement. The stability study shows that the prepared optimized formulations were stable under the testing conditions as there were not any significant changes seen.

Prof. Prashant Burange is currently working at P.R. Pote Patil College of Pharmacy, Amravati. He is currently working in the Department of Pharmaceutical Chemistry. He has industrial working experience of more than 6 years and academic experience of more than 4 years. He is having an interest in analytical, medicinal chemistry along with regulatory affairs. He is having many articles published in various national and international journals.

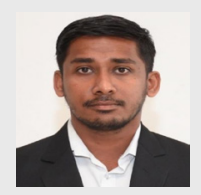

Prof. Yashdeepsingh Thakur is currently working at P.R. Pote Patil College of Pharmacy, Amravati. $\mathrm{He}$ is currently working in the Diploma in Pharmacy Department. He is currently having experience of academics of more than 2 years and has various articles published in National Journals.

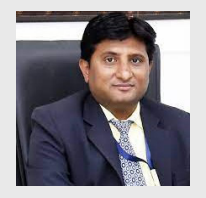

Dr. Mukund Tawar is currently working at P.R. Pote Patil College of Pharmacy, Amravati as a Principal of the Institute. He is having his Ph.D. in Pharmaceutics Department and has more than 15 years of experience in academics. He is having more than 20 publications in various National and International Journals. His area of interest includes Novel Drug Delivery System, Research and Development, Formulation and Development, and Various other research fields in Pharmacy.

Cite this article: Malviya V, Burange P, Thakur Y, Tawar M. Enhancement of Solubility and Dissolution Rate of Atazanavir sulfate by Nanocrystallization. Indian $\mathrm{J}$ of Pharmaceutical Education and Research. 2021;55(3s):s672-s680. 